American Journal of Applied Sciences 7 (9): 1248-1253, 2010

ISSN 1546-9239

(C) 2010 Science Publications

\title{
Parametric Deduction Optimization for Surface Roughness
}

\author{
Tian-Syung Lan \\ Department of Information Management, Yu Da University \\ Miaoli County, Taiwan 361, ROC
}

\begin{abstract}
Problem statement: Surface roughness is a major consideration in modern Computer Numerical Control (CNC) turning industry. Most existing optimization researches for CNC finish turning were either accomplished within certain manufacturing circumstances, or achieved through numerous equipment operations. Therefore, a general deduction optimization scheme is deemed to be necessary for the industry. Approach: In this study, four parameters (cutting depth, feed rate, speed, tool nose runoff) with three levels (low, medium, high) were considered to optimize the surface roughness for Computer Numerical Control (CNC) finish turning. Additionally, twenty-seven fuzzy control rules using trapezoid membership function with respective to seventeen linguistic grades for the surface roughness were constructed. Considering thirty input and eighty output intervals, the defuzzification using center of gravity was moreover completed. Through the Taguchi experiment, the optimum general deduction parameters can then be received. Results: The confirmation experiment for optimum deduction parameters was furthermore performed on an ECOCA-3807 CNC lathe. It was shown that the surface roughness from the fuzzy deduction optimization parameters are significantly advanced comparing to those from benchmark. Conclusion: This study not only proposed a parametric deduction optimization scheme using orthogonal array, but also contributed the satisfactory fuzzy approach to the surface roughness for CNC turning with profound insight.
\end{abstract}

Key words: Computer numerical control, orthogonal array, fuzzy deduction, surface roughness

\section{INTRODUCTION}

Machining operations have been the core of the manufacturing industry since the industrial revolution (Rao, 2006). The existing optimization researches for Computer Numerical Controlled (CNC) turning were either simulated within particular manufacturing circumstances (Sivarao et al., 2009; Lin et al., 2001; Lin, 1998; Meng et al., 2000), or achieved through numerous frequent equipment operations (Kopac et al., 2002; Tosun and Ozler, 2004). Nevertheless, these are regarded as computing simulations and the applicability to real world industry is still uncertain. Therefore, a general optimization scheme without equipment operations is deemed to be necessarily developed.

Surface roughness is commonly considered as a major manufacturing goal (Tosun and Ozler, 2004) for turning operations in many of the existing researches. The machining process on a CNC lathe is programmed by speed, feed rate and cutting depth, which are frequently determined based on the job shop experiences. However, the machine performance and the product characteristics are not guaranteed to be acceptable. Therefore, the optimum turning conditions have to be accomplished. It is mentioned that the tool nose run-off will affect the performance of the machining process (Yeh and Lai, 1995). Therefore, the tool nose run-off is also selected as one of the control factors in this study.

Parameter optimization for surface roughness is a hard-solving issue because of the interactions between parameters. Problems related to the enhancement of product quality and production efficiency can always be related to the optimization procedures. Taguchi method, an experimental design method, has been widely applied to many industries. It can not only optimize quality characteristics through the setting of design parameters, but also reduce the sensitivity of the system performance to sources of variation (Huh et al., 2003; Suhail et al., 2010; Kim et al., 2003; Benhamid and Othman, 2009). The Taguchi method adopts a set of orthogonal arrays to investigate the effect of parameters on specific quality characteristics to decide the optimum parameter combination. These kinds of arrays use a small number of experimental runs to analyze the quality effects of parameters as well as the optimum combination of parameters.

To achieve the deduction optimization, it is necessary to first describe the dynamic behavior of the system to be controlled. Because of the number, 
complexity and unclear, vague nature of the variables of the dynamic systems that may influence the decision maker's decision, fuzzy set theory is the most suitable solution (Zadeh, 1965; Zimmerman, 2001). Fuzzy linguistic models permit the translation of verbal expressions into numerical ones (Gungor and Arikan, 2007). Therefore, the input output relationship of the process can be described by the collection of fuzzy control rules involving linguistic variables rather than a complicated dynamic mathematical model.

With all the viewpoints above, this study considers four parameters (cutting depth, feed rate, speed, tool nose runoff) with three levels (low, medium, high) to optimize the surface roughness in CNC finish turning. The fuzzy control rules using triangle membership function with respective to seventeen linguistic grades for surface roughness are additionally constructed. The defuzzification is then quantified using center of gravity and introduced as the Signal-to-Noise $(\mathrm{S} / \mathrm{N})$ ratio to Taguchi experiment and thus the optimum deduction parameters can then be received. This study definitely proposes a fuzzy deduction general optimization approach and satisfactory fuzzy linguistic technique for improving surface roughness in CNC turning with profound insight.

\section{MATERIALS AND METHODS}

In this study, the variable quantification and deduction optimization for CNC turning operations are proposed using fuzzy set theory and Taguchi method respectively. They are described as below.

Fuzzy set theory: Let $X$ be a universe of discourse, $\tilde{\mathrm{A}}$ is a fuzzy subset of $X$ if for all $\mathrm{x} \in \mathrm{X}$, there is a number $\mu_{\tilde{A}}(x) \in[0,1]$ assigned to represent the membership of $\mathrm{x}$ to $\tilde{\mathrm{A}}$ and $\mu_{\tilde{\mathrm{A}}}(\mathrm{x})$ is called the membership function of $\tilde{A}$. A trapezoid fuzzy number $\tilde{A}$ can be defined by a trip-let (a, b, c, d) (Fig. 1) (Kaufmann et al., 1991). The membership function is defined as:

$\mu_{\tilde{A}}(x: a, b, c, d)=\left\{\begin{array}{cc}\frac{x-a}{b-a} & a<x \leq b \\ 1 & b<x \leq c \\ \frac{x-d}{c-d} & c<x \leq d \\ 0 & \text { otherwise }\end{array}\right.$

where, $\mathrm{F}\left(\mathrm{x}_{\mathrm{i}}\right)$ is the final rating of activity, $\mu_{\tilde{\mathrm{A}}}\left(\mathrm{x}_{\mathrm{i}}\right)$ describes the membership function of fuzzy set $\tilde{A}$.

Taguchi method: The Taguchi method is a robust design method technique (Palanikumar, 2008; Ross, 
1995), which provides a simple way to design an efficient and cost effective experiment. In order to efficiently reduce the numbers of conventional experimental tasks, the orthogonal array (Senapati et al., 2007; Wei et al., 2002) by using design parameters (control factors) in column and standard quantities (levels) in row is proposed and further adopted. The performance measure, Signal-to-Noise ratio $(\mathrm{S} / \mathrm{N})$ (Park et al., 2005) proposed by Taguchi is used to obtain the optimal parameter combinations. The larger $\mathrm{S} / \mathrm{N}$ means the relation to the quality will become better. The lower quality characteristic will be regarded as a better result when considering the smaller-the-best quality. The related $\mathrm{S} / \mathrm{N}$ ratio is defined as:

$\mathrm{S} / \mathrm{N}=-10\left(\log \sum_{\mathrm{i}=1}^{\mathrm{n}} \frac{\mathrm{y}_{\mathrm{i}}^{2}}{\mathrm{n}}\right)(\mathrm{dB})$

Where:

$\mathrm{n}=$ The number of experiments for each experimental set

$\mathrm{y}_{\mathrm{i}}=$ The quality characteristic at the i-th experiment

On the contrary, the larger quality characteristic will have better result $t$ when considering the largerthe-best quality, therefore, by taking the inverse of quality characteristic into Eq. 13 , the related $\mathrm{S} / \mathrm{N}$ ratio can also be deduced and shown in Eq. 14:

$\mathrm{S} / \mathrm{N}=-10\left(\log \sum_{\mathrm{i}=1}^{\mathrm{n}} \frac{1 / \mathrm{y}_{\mathrm{i}}^{2}}{\mathrm{n}}\right)(\mathrm{dB})$

In this study, the defuzification result is introduced to the Taguchi experiment as the $\mathrm{S} / \mathrm{N}$ ratio. Therefore, it is judged as the quality of smaller-the-best. In addition to the $\mathrm{S} / \mathrm{N}$ ratio, a statistical Analysis of Variance (ANOVA) (Wu and Chyu, 2002) can be employed to indicate the impact of process parameters. In this way, the optimal levels of process parameters can be estimated.

Research design: Surface roughness is considered the major goal in this study. Four parameters with three levels are selected to optimize the finish turning based on the orthogonal array. Additionally, twenty-seven fuzzy control rules with respective to seventeen linguistic grades for each attribute are constructed. Considering thirty input and eighty output intervals, the defuzzification using center of gravity is thus completed for the Taguchi experiment and the optimum deduction parameters can then be received.
Construction of orthogonal array: In this study, the four turning parameters (A-speed, B-cutting depth, Cfeed rate and D-tool nose runoff) (Lan and Wang, 2009) with three different levels (low, medium and high) (Table 1) are constructed for the deduction optimization of machining operation. In Table 1, the three levels of speed, cutting depth and feed rate are considered according to the machining handbook suggested by the tool manufacturer. The tool nose runoff is positioned by using different shims located under the tool holder. The orthogonal array is then selected to perform the nine sets of deduction experiments.

\begin{tabular}{|c|c|c|c|c|}
\hline \multirow[b]{2}{*}{ Experiment } & \multicolumn{4}{|c|}{ Parameter } \\
\hline & $\begin{array}{l}\text { A } \\
\text { (speed) }\end{array}$ & $\begin{array}{l}\text { B (cutting } \\
\text { depth) }\end{array}$ & $\begin{array}{l}\mathrm{C} \\
\text { (feed rate) }\end{array}$ & $\begin{array}{l}\mathrm{D} \text { (tool nose } \\
\text { runoff) }\end{array}$ \\
\hline 1 & Low & Low & Low & Low \\
\hline 2 & Low & Medium & Medium & Medium \\
\hline 3 & Low & High & High & High \\
\hline 4 & Medium & Low & Medium & High \\
\hline 5 & Medium & Medium & High & Low \\
\hline 6 & Medium & High & Low & Medium \\
\hline 7 & High & Low & High & Medium \\
\hline 8 & High & Medium & Low & High \\
\hline 9 & High & High & Medium & Low \\
\hline
\end{tabular}

Table 2: Fuzzy rules for surface roughness

\begin{tabular}{|c|c|c|c|}
\hline Rules & Speed & Feed rate & Deduction \\
\hline 1 & Low & Low & medium \\
\hline 2 & Low & Medium & large \\
\hline 3 & Low & High & largest \\
\hline 4 & Low & Low & medium \\
\hline 5 & Low & Medium & large \\
\hline 6 & Low & High & largest \\
\hline 7 & Low & Low & medium \\
\hline 8 & Low & Medium & large \\
\hline 9 & Low & High & largest \\
\hline 10 & Medium & Low & small \\
\hline 11 & Medium & Medium & medium \\
\hline 12 & Medium & High & large \\
\hline 13 & Medium & Low & small \\
\hline 14 & Medium & Medium & medium \\
\hline 15 & Medium & High & large \\
\hline 16 & Medium & Low & small \\
\hline 17 & Medium & Medium & medium \\
\hline 18 & Medium & High & large \\
\hline 19 & High & Low & smallest \\
\hline 20 & High & Medium & small \\
\hline 21 & High & High & medium \\
\hline 22 & High & Low & smallest \\
\hline 23 & High & Medium & small \\
\hline 24 & High & High & medium \\
\hline 25 & High & Low & smallest \\
\hline 26 & High & Medium & small \\
\hline 27 & High & High & medium \\
\hline
\end{tabular}

Table 3: Trapezoid ranges of three linguistic levels for parameters

\begin{tabular}{llll}
\hline Linguistic level & Low & Medium & High \\
\hline Range & {$[0,12.5,15]$} & {$[0,2.5,27.5,30]$} & {$[15,17.5,30]$} \\
\hline
\end{tabular}


Am. J. Applied Sci., 7 (9): 1248-1253, 2010

Table 4: Trapezoid ranges of seventeen linguistic levels for attributes

\begin{tabular}{llllll}
\hline Linguistic level & Smallest & Extreme small & Super small & Small small & Small \\
\hline Range & {$[0,2.5,5]$} & {$[0,2.5,7.5,10]$} & {$[5,7.5,12.5,15]$} & {$[10,12.5,17.5,20]$} & {$[15,17.5,22.5,25]$} \\
Smaller & Much smaller & A little smaller & Medium & A little larger & Much larger \\
{$[20,22.5,27.5,30]$} & {$[25,27.5,32.5,35]$} & {$[30,32.5,37.5,40]$} & {$[35,37.5,42.5,45]$} & {$[40,42.5,47.5,50]$} & {$[45,47.5,52.5,55]$} \\
Larger & Large & Large large & Super large & Extreme large & Largest \\
{$[50,52.5,57.5,60]$} & {$[55,57.5,62.5,65]$} & {$[60,62.5,67.5,70]$} & {$[65,67.5,72.5,75]$} & {$[70,72.5,77.5,80]$} & {$[75,77.5,80]$} \\
\hline
\end{tabular}

Table 5: Quantified results for linguistic results

\begin{tabular}{lllllllll}
\hline Linguistic level & Smallest & Extreme small & Super small & Small small & Small & Smaller & Much smaller & A little smaller \\
\hline Defuzzification & 1.666667 & 5 & 10 & 15 & 20 & 25 & 30 & 35 \\
Medium & A little larger & Much larger & Larger & Large & Large large & Super large & Extreme large & Largest \\
40 & 45 & 50 & 55 & 60 & 65 & 70 & 75 & 78.33333 \\
\hline
\end{tabular}

Fuzzy control rules: The twenty-seven fuzzy control rules with respective to seventeen grades for the surface roughness in this study are determined. From the existing literature (Petropoulos et al., 2006), it is found that the surface roughness can be expressed as:

$$
R_{i}(i=a, z D, t, p, q, 3 z)=C_{i} V^{m i} f^{n i}
$$

where the machining speed (V) and feed rate (f) are concluded as priority parameters to surface roughness. Therefore, the fuzzy rules can be described as shown in Table 2.

Defuzzification: In this study, the three parameter levels are selected based on the Taguchi experimental method, therefore, each triangle membership function is related to the peak point of its fuzzy area. Considering thirty input and eighty output intervals, the defuzzification of seventeen linguistic grades using center of gravity can then be completed. The degree of membership for input (parameter) and output (attribute) can be described as shown in Table 3 and 4 respectively. Utilizing the average value of the fuzzy set to represent the entire set, we then have the quantified result for the fuzzy item of seventeen linguistic grades as shown in Table 5.

\section{RESULTS AND DISCUSSION}

By considering the parameter combinations of the nine sets of experiment based on the $\mathrm{L}_{9}\left(3^{4}\right)$ orthogonal array, the quantified results from fuzzy deduction for the surface roughness are determined and shown as Table 6. Introducing the deduction results as the Signal to Noise ratio $(\mathrm{S} / \mathrm{N})$ for surface roughness under smaller-the-best expectation, the results of factor responses are calculated and listed in Table 7. The mean effects for $\mathrm{S} / \mathrm{N}$ ratios are then drawn by MINITAB 14 and shown as Fig. 2. Therefore, the optimum fuzzy deduction multiattribute turning parameters are found to be A (Low), B (High), C (High) and D (Low or High).
Table 6: Fuzzy deduction results

\begin{tabular}{lc}
\hline Attributes experiment & Surface roughness \\
\hline 1 & 40.0000 \\
2 & 60.0000 \\
3 & 70.8854 \\
4 & 60.0000 \\
5 & 40.0000 \\
6 & 20.0000 \\
7 & 40.0000 \\
8 & 9.1146 \\
9 & 60.0000 \\
\hline
\end{tabular}

Table 7: Result of factor responses

\begin{tabular}{|c|c|c|c|c|}
\hline \multirow[b]{2}{*}{ Level } & \multicolumn{4}{|c|}{ Parameter } \\
\hline & A & B & $\mathrm{C}$ & $\mathrm{D}$ \\
\hline Low & 56.96 & 46.67 & 23.04 & 46.67 \\
\hline Medium & 40.00 & 36.37 & 60.00 & 40.00 \\
\hline High & 36.37 & 50.30 & 50.30 & 46.67 \\
\hline Delta & 20.59 & 13.92 & 36.96 & 6.67 \\
\hline Rank & 2.00 & 3.00 & 1.00 & 4.00 \\
\hline
\end{tabular}

Table 8: Parameters and levels

\begin{tabular}{|c|c|c|c|}
\hline \multirow[b]{2}{*}{ Parameter } & \multicolumn{3}{|l|}{ Level } \\
\hline & $\begin{array}{l}\text { Low } \\
\text { (level 1) }\end{array}$ & $\begin{array}{l}\text { Medium } \\
\text { (level 2) }\end{array}$ & $\begin{array}{l}\text { High } \\
\text { (level 3) }\end{array}$ \\
\hline A: Speed (m/min) & 150.0 & 200.00 & 250.0 \\
\hline B: Cutting depth (mm) & 1.0 & 2.00 & 3.0 \\
\hline C: Feed rate (mm/rev) & 0.2 & 0.30 & 0.4 \\
\hline D: Tool nose runoff (mm) & -0.1 & \pm 0.03 & 0.1 \\
\hline
\end{tabular}

The finishing diameter turning operation of S45C $(\varphi 45 \mathrm{~mm} \times 250 \mathrm{~mm})$ work piece on an ECOCA-3807 CNC lathe is arranged for the experiment. The TOSHIBA WTJNR2020K16 tool holder with MITSUBISHI NX2525 insert is utilized as the cutting tool. The four turning parameters (speed, cutting depth, feed rate and tool nose runoff) with three different levels (low, medium and high) (Table 8) are experimentally distinguished for the machining operation on the basis of $\mathrm{L}_{9}\left(3^{4}\right)$ orthogonal array. In Table 8, the three levels of speed, cutting depth and feed rate are identified from the machining handbook suggested by the tool manufacturer. The tool nose 
runoff is positioned by using different shims located under the tool holder and determined by measuring the tip after face turned the work piece. When the tool nose is set approximately $0.1 \mathrm{~mm}$ higher (lower) than the center of the work piece, it is regard as "High (Low)". When the tool nose is set within $\pm 0.03 \mathrm{~mm}$, it is considered as "Medium".

The surface Roughness $\left(R_{a}\right)$ of machined work pieces are measured on the MITSUTOYO SURFTEST at three different segments of $40 \mathrm{~mm}$, $80 \mathrm{~mm}$ and $120 \mathrm{~mm}$ from the face, therefore, the average data are received as the attribute of surface roughness. To verify the applicability of the optimum result achieved by our proposed deduction optimization technique, the machining operations under both fuzzy linguistic optimization parameters and benchmark parameters; A (medium), B (medium), C (medium), D (medium), which are often introduced into the confirmation experiment in many of the studies (Tosun and Ozler, 2004; Lin and Lin, 2006) for comparison to the optimum parameters, are performed on the CNC lathe. The machined results are concluded and listed in Table 9. From Table 9, it is observed that the surface roughness under fuzzy deduction parameters are significantly improved by 14.4 and $23.1 \%$ respectively and the average result is also improved by $18.75 \%$ from the benchmark parameters. It is shown that our proposed general deduction optimization technique can really advance the surface roughness for CNC turning.

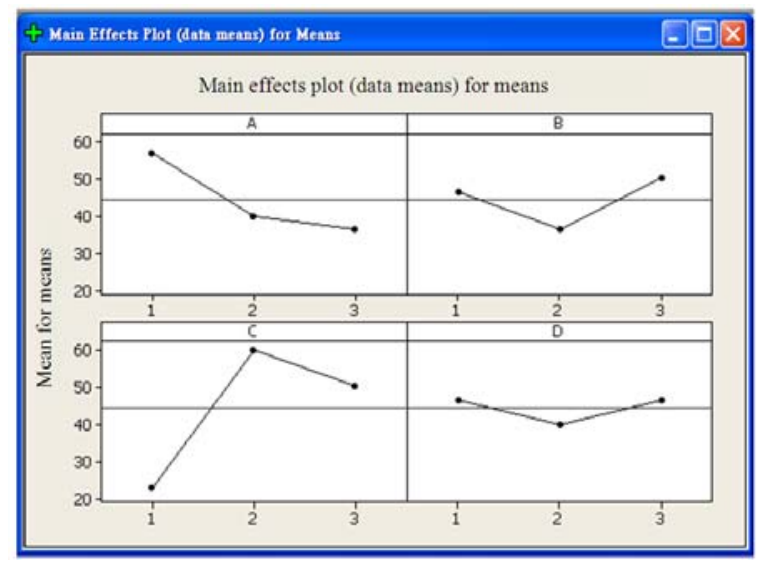

Fig. 2: Plot of main effects

Table 9: Confirmation results

\begin{tabular}{ll}
\hline & Surface roughness \\
\hline $\begin{array}{l}\text { Fuzzy deduction optimization parameters } \\
\text { (A1B3C3D1) }\end{array}$ & $0.7900 \mu \mathrm{m}$ \\
$\begin{array}{l}\text { Fuzzy deduction optimization parameters } \\
\text { (A1B3C3D3) }\end{array}$ & $0.7100 \mu \mathrm{m}$ \\
Benchmark parameters (A2B2C2D2) & $0.9233 \mu \mathrm{m}$ \\
\hline
\end{tabular}

\section{CONCLUSION}

In this study, the parametric deduction scheme was proposed and applied to achieve the optimum CNC finish turning parameters under the considerations of surface roughness. A confirmation experiment of the optimum deduction parameters was conducted to indicate the effectiveness of the proposed fuzzy optimization method. Through the confirmation test, the experimental results validate the potency that the surface roughness can be advanced from our parametric deduction optimization technique.

Parametric optimization is a hard-solving issue because of the interactions between parameters. This study not only proposes a deduction optimization approach using orthogonal array, but also contributes the satisfactory fuzzy technique for improving the surface roughness in CNC turning with profound insight. The competition of manufacturing industry will then be economically excited through the proposed development in this study.

\section{ACKNOWLEDGEMENT}

Financial support for this study was provided by the National Science Council Taiwan, R.O.C., under the contract of NSC 98-2221-E-412-002.

\section{REFERENCES}

Benhamid, M. and M.B. Othman, 2009. Hardware implementation of a genetic algorithm based canonical singed digit multiplierless fast Fourier transform processor for multiband orthogonal frequency division multiplexing ultra wideband applications. J. Math. Stat., 5: 241-250. http://www.scipub.org/fulltext/jms2/jms254241-250.pdf

Gungor, Z. and F. Arikan, 2007. Using fuzzy decision making system to improve quality-based investment. J. Intell. Manuf., 18: 197-207. DOI: 10.1007/s10845-007-0016-x

Huh, H., J.H. Heo and H.W. Lee, 2003. Optimization of a roller leveling process for Al7001T9 pipes with finite element analysis and Taguchi method. Int. J. Mach. Tool Manuf., 43: 345-350. DOI: 10.1016/S0890-6955(02)00269-9

Kaufmann, A., M.M. Gupta and B. Esposito, 1991. Introduction to Fuzzy Arithmetic Theory and Applications. 1st Edn., Van Nostrand Reinhold Company, New York, ISBN: 10: 0442008996, pp: 384.

Kim, S.J., K.S. Kim and H. Jang, 2003. Optimization of manufacturing parameters for a brake lining using Taguchi method. J. Mater. Process. Technol., 136: 202-208. DOI: $10.1016 /$ S09240136(03)00159-6 
Kopac, J., M. Bahor and M. Sokovi, 2002. Optimal machining for achieving the desired surface roughness in fine turning of cold pre-formed steel workpiece. Int. J. Mach. Tool Manuf., 42: 707-716. DOI: 10.1016/S0890-6955(01)00163-8

Lan, T.S. and M.Y. Wang, 2009. Competitive parameter optimization of multi-quality CNC turning. Int. J. Adv. Manuf. Technol., 41: 820-826. DOI: $10.1007 / \mathrm{s} 00170-008-1495-4$

Lin, J.L. and J.F. Lin, 2006. Grey theory applied to evaluate the tribological performances of the a$\mathrm{CH}(\mathrm{N})$ coating films prepared by differing the nitrogen content and the film thickness. Int. J. Adv. Manuf. Technol., 27: 845-853. DOI: 10.1007/s00170-004-2294-1

Lin, W.S., 1998. The study of machining accuracy and tool wear reliability. Ph.D. Thesis, National Central University.

Lin, W.S., B.Y. Lee and C.L. Wu, 2001. Modeling the surface roughness and cutting force for turning. J. Mater Process. Technol., 108: 286-293. DOI: 10.1016/S0924-0136(00)00835-9

Meng, Q., J.A. Arsecularatne and P. Mathew, 2000. Calculation of optimum cutting conditions for turning operations using a machining theory. Int. J. Adv. Manuf. Technol., 40: 1709-1733. DOI: 10.1016/S0890-6955(00)00026-2

Palanikumar, K., 2008. Application of Taguchi and response surface methodologies for surface roughness in machining glass fiber reinforced plastics by PCD tooling. Int. J. Adv. Manuf. Technol., 36: 19-27. DOI: 10.1007/s00170-0060811-0

Park, J.H., K.M. Yang and K.S. Kang, 2005. A quality function deployment methodology with signal and noise ratio for improvement of Wassermann's weights. Int. J. Adv. Manuf. Technol., 26: 631-637. DOI: $10.1007 / \mathrm{s} 00170-003-2036-9$

Petropoulos, G., F. Mata and J.P. Davim, 2006. Statistical study of surface roughness in turning of peek composites. Mater. Design, 29: 218-223. DOI: 10.1016/j.matdes.2006.11.005

Ross, P.J., 1995. Taguchi Techniques for Quality Engineering. 2nd Edn., McGraw-Hill, New York, ISBN: 10: 0070539588, pp: 329.
Rao, R.V., 2006. Machinability evaluation of work materials using a combined multiple attribute decision-making method. Int. J. Adv. Manuf. Technol., 28: 221-227. DOI: 10.1007/s00170-0042348-4

Suhail, A.H., N. Ismail, S.V. Wong and N.A.A. Jalil, 2010. Optimization of cutting parameters based on surface roughness and assistance of workpiece surface temperature in turning process. Am. J. Eng. Applied Sci., 3: 102-108. http://www.scipub.org/fulltext/ajeas/ajeas31102-108.pdf

Senapati, M.R., I. Vijaya and P.K. Dash, 2007. Rule extraction from radial basis functional neural networks by using particle swarm optimization. J. Comput. $\quad$ Sci., $\quad 3$ : 592-599. http://www.scipub.org/fulltext/jcs/jcs38592599.pdf

Sivarao, P. Brevern and N.S.M. El-Tayeb, 2009. A new approach of adaptive network-based fuzzy inference system modeling in laser processing-a Graphical User Interface (GUI) based. J. Comput. Sci., $\quad$ 5: 704-710. http://www.scipub.org/fulltext/jcs/jcs510704-710.pdf

Tosun, N. and L. Ozler, 2004. Optimization for hot turning operations with multiple performance characteristics. Int. J. Adv. Manuf. Technol., 23: 777-782. DOI: 10.1007/s00170-003-1672-4

Wei, H.S., S.C. Hwang and S.J. Liu, 2002. Analysis for the optimum conditions in derrick hook by using Taguchi method. MS.c. Thesis, Nation Pingtung University of Science and Technology.

Wu, F.C. and C.C. Chyu, 2002. A comparative study on Taguchi's SN ratio, minimizing MSD and variance for nominal-the-best characteristic experiment. Int. J. Adv. Manuf. Technol., 20: 655-659. DOI: 10.1007/s001700200203

Yeh, L.J. and G.J. Lai, 1995. A study on the monitoring and suppression system for turning slender workpieces. Proc. Inst. Mech. Eng. Part B. J. Eng. Manuf., 209: 227-236. http://cat.inist.fr/?aModele=afficheN\&cpsidt=3577156

Zadeh, L.A., 1965. Fuzzy sets. Inform. Control, 8: 338-353. DOI: 10.1016/S0019-9958(65)90241-X

Zimmerman, H.J., 2001. Fuzzy Sets Theory and its Applications. 4th Edn., Springer, Boston. ISBN: 10: 0792374355, pp: 514. 